\title{
Considerações sobre o princípio de proporcionalidade entre a causa e 0 efeito nos Diálogos de Hume
}

Considerations on the Principle of Proportionality Between Cause and Effect in Hume's Dialogues

\section{Marília Côrtes de Ferraz}

Professora adunta

Universidade Estadual do Norte do Paraná [UENP]

\section{RESUMO}

Trata-se, neste artigo, de analisar o princípio fundamental - like effects prove like causes - sobre o qual Cleanto, nos Diálogos sobre a Religião Natural de Hume, apoia sua defesa do argumento do desígnio, bem como examinar a estratégia argumentativa de Filo para enfraquecer paulatinamente a força do argumento defendido por Cleanto.

\section{PALAVRAS-CHAVE}

Argumento do desígnio; Analogia; Proporcionalidade; Causa e efeito.

\begin{abstract}
The aim of this article is to analyze the fundamental principle - like effects prove like causes - on which Cleanthes supports his defense of the design argument in Hume's Dialogues Concerning Natural Religion. It's also intended to examine Philo's argumentative strategy to gradually weaken the strength of the argument advocated by Cleanthes.
\end{abstract}

\section{KEY WORDS}

Design argument; Analogy;

Proportionality; Cause and effect. 


\section{Introdução}

O tema central dos Diálogos sobre a religiāo natural (D) dirige-se a uma investigação do argumento do desígnio, defendido pelo personagem Cleanto, segundo o qual a existência de um criador sumamente inteligente, justo, poderoso e benevolente pode ser inferida a partir da ordem e da beleza que observamos no mundo. Este argumento reclama uma resposta para a questão sobre se temos fundamentos razoáveis para acreditar numa divindade (entendida como princípio originário do universo ou causa primeira) dotada de suprema inteligência, atributos e intençóes morais.

Hume já havia tratado desse argumento também na seção II da Investigação sobre o entendimento humano (EHU). Penso que essa seção, intitulada De uma providência particular e de um estado vindouro, pode e deve ser vista como uma importante peça introdutória à crítica que Hume faz ao argumento do desígnio, bem como um componente essencial de sua crítica à religião natural em geral. Nela podemos encontrar muitos argumentos que serão desenvolvidos de maneira mais profunda e completa nos Diálogos. Todavia, embora Hume se sirva nessa seção do argumento do desígnio como um instrumento de sua crítica à religiáo em geral, seu principal objetivo é, conforme o título indica, discutir a existência de uma providência particular ${ }^{1}$ e de um estado vindouro. Aí o ponto de Hume é mostrar que não temos boas razóes para argumentar em favor de uma providência particular e de uma vida pós-morte com base no argumento do desígnio ${ }^{2}$, embora ele revele que não está, propriamente, a negar a existência divina. Ao contrário, Hume enfatiza que o principal ou único argumento aceitável em favor dela deriva da ordem natural. Contudo, a seçáo abrange também aspectos ulteriores. Hume defende que negar a providência divina e uma vida pós-morte não coloca a ordem social e política sob ameaça, uma vez que a moral, entendida aqui especialmente como pré-requisito para a manutenção da paz da sociedade e segurança do governo, pode, conforme algumas teses defendidas em outras partes da EHU e também em outras obras, ser fundamentada ao longo de linhas laicas, sem qualquer apelo a mandamentos morais divinos. ${ }^{3}$ Quer dizer, na seção II da EHU o problema de Hume gira em torno de saber o quanto essas questóes

1 Conforme esclarece Beauchamp, a providência particular refere-se à providência e intervençáo divinas nos acontecimentos particulares dos indivíduos. A providência geral é a provisão divina de tudo e de todas as coisas por meio das leis universais da natureza, isto é, já inscritas nessas leis (cf. Hume, 1999, annotations section II, p. 254).

2 Vale dizer que náo temos boas razóes para argumentar em favor de uma providência particular e um estado vindouro com base em qualquer outro argumento da religião natural. Afora a concepção geral de Hume que aponta para isso, nos Diálogos $(4 \S 5)$ Philo diz que se esforçará para provar a Cleanthes "que não há nenhum fundamento para supor que a mente divina tenha formulado um plano do mundo" (Hume, 1993, p. 62), muito menos, creio poder depreender, um plano particular para cada indivíduo.

3 Por exemplo: livros 2 e 3 do Tratado da natureza humana (T); EHU 8; Investigação sobre os princípios da moral (EPM); Diálogos 12 . 
dizem respeito ao interesse público. Mas, nos Diálogos, Hume examina minuciosamente o argumento do desígnio, a fim de mostrar que, na melhor das hipóteses, este argumento produz apenas conclusôes prováveis, e que a disputa entre teístas filosóficos e céticos filosóficos (sendo que a linha que separa os céticos filosóficos dos ateus é extremamente tênue) é, ao fim e ao cabo, estéril.

Em linhas gerais, o argumento do desígnio procede por analogia, explorando as similaridades entre os artifícios da natureza e certos artefatos humanos. Podemos observar que a natureza exibe ordem e desígnio: as estaçóes do tempo vêm e vão com certa regularidade e, justamente por isso, sáo previsíveis, permitindo-nos plantar e colher em tempos propícios. Por conta dessa ordem e regularidade que a natureza exibe, podemos predizer com cada vez mais acurácia o movimento das marés, do sol, da lua, da terra e dos planetas, as variaçóes do clima, o tempo de gestaçáo e vida dos animais, etc. Aliás, nem precisamos olhar para os céus, ou mesmo para fora de nós. Olhemos para nós mesmos. Pensemos nos desdobramentos dos cromossomos, no mecanismo dos nossos olhos e de nossa visão. Percebamos nossos batimentos cardíacos, mensuremos nossa pressão. Enfim, reparemos nas funçóes e ajustes de todas essas partes. Esta organizaçáo natural convida-nos ou, talvez, constranja-nos a compará-la com um tipo de ordem que depende de um planejamento inteligente, como, por exemplo, a construçáo de casas, navios, relógios e barcos. Sobre o princípio de que efeitos semelhantes requerem causas semelhantes, inferimos por analogia que a causa da ordem natural deve ser um Ser inteligente (e que esse ser é Deus). Os proponentes do argumento do desígnio defendem, a partir disso, que a hipótese de um designer inteligente como causa ou princípio do mundo e de todas as coisas é a melhor explicaçáo para certos fenômenos observáveis na natureza, tais como a harmonia, a ordem e a adaptação dos meios aos fins que ela exibe (cf. Merrill, 2008, p. 9I).

Nos Diálogos, Cleanto é o proponente do argumento do desígnio e Filo o personagem que rejeita este argumento (além de Demea). No entanto, Filo não o rejeita de imediato e tampouco tout à fait, como o faz Demea. O que Filo faz é apontar paulatinamente a fraqueza dos argumentos em favor dessa hipótese, diminuindo, assim, significativamente a sua força. Tal como Hume já havia estabelecido na seção II da EHU, Filo defende o princípio segundo o qual não devemos dotar a causa ou causas (no caso deste argumento o designer inteligente divino) da ordem e desígnios do universo, com mais e maiores atributos do que aqueles que sáo estritamente requeridos para seus efeitos, e mostra que, embora seja possível que a divindade possua atributos que não nos são conhecidos, não podemos com segurança inferir tais atributos a partir das evidências que temos. Assim, Filo questiona a força da analogia sobre a qual o argumento do desígnio se apoia, colocando um dilema para seus proponentes: ou a analogia é muito fraca, ou muito forte para produzir a conclusão desejada. Ela seria fraca porque há uma grande disparidade entre os fenômenos ou objetos comparados - os produtos da natureza e os produtos dos artifícios huma- 
nos. Podemos comparar macacos e seres humanos porque temos conhecimento empírico da fisiologia e anatomia dessas duas classes de seres. Mas não temos nenhuma base comparativa consistente para assemelhar o trabalho de um relojoeiro com o trabalho de uma divindade que produz mundos. Um lado da analogia é muito bem conhecido (o trabalho do relojoeiro), mas o outro é praticamente desconhecido (cf. Merrill, 2008, p. 92).

Por outro lado, se admitimos mais estreitamente a requerida analogia, deparamonos também com consequências indesejáveis para os defensores do teísmo. Por exemplo: construir casas, em geral, requer a cooperação de vários trabalhadores, tais como arquitetos, carpinteiros, encanadores e pedreiros. Analogamente, isso nos permitiria concluir que o universo foi criado por uma pluralidade de criadores (nesse caso, várias divindades). ${ }^{4}$ Contudo, os proponentes do argumento do desígnio não têm em mente nem esposam o politeísmo, mas sim o monoteísmo. Portanto, a analogia não conduz à conclusão desejada. Ora, por que assumir que há somente um designer se, em geral, os artefatos humanos são produzidos por vários artífices? Pode-se conjeturar que, talvez, o universo tenha sido construído por uma equipe, ou várias equipes que trabalharam de geração em geração. Talvez o resultado seja um refinamento gradual temporal por meio de um longo processo de tentativas e erros. Além disso, se aproximarmos demais o artífice da ordem e desígnio do universo dos artífices humanos, alguém poderia argumentar que artífices humanos cometem más açôes, podem melhorar seus produtos com a prática, são corporais e mortais. Pois bem, pode-se dizer o mesmo em relação à divindade? Filo argumenta que as dissimilaridades entre os artefatos humanos e o universo são espantosas. $\mathrm{O}$ argumento versa sobre objetos únicos: Deus (como causa) e o universo (como efeito). Sendo assim, não podemos observar conjunçóes constantes de casos similares - uma das regras fundamentais, segundo Hume, para julgarmos qualquer questão sobre causa e efeito. Nossa inteligência não é perfeita e o mundo também exibe evidentes imperfeiçóes. $\mathrm{O}$ universo se apresenta tanto em ordem quanto em desordem. Talvez, cogita Filo, ele seja apenas uma obra mal acabada de um designer senil e descuidado. Ademais, não temos nenhuma experiência da origem de mundos. Experienciamos somente uma pequena parte do universo, e conhecemos muito pouco sobre ele, por um período muito curto de tempo. Assim sendo, com que propriedade poderíamos transferir para o todo uma conclusão acerca de suas partes (Hume, 1993, p. 49)?

\footnotetext{
4 Alguém poderia argumentar que uma coisa é falar em construtores ou, digamos assim, executores de uma casa; outra coisa é falar num designer (somente num projetista). Um designer de uma casa pode muito bem projetá-la sozinho e depois jogar o projeto nas mãos de alguns executores. É verdade, mas, em geral, ele não poderá executá-la sozinho. Ao menos isso não é comum para grandes projetos. Supóe-se que Deus pensou o mundo e o fez num Fiat. Um designer humano jamais poderia pensar o projeto de uma casa e, num Fiat, construí-la. Eis, então, para ilustrar, mais uma das grandes disparidades entre o designer divino (que, aliás, de acordo com a tese de Cleanthes, náo é só designer do mundo, mas também seu criador) e o humano.
} 


\section{As primeiras objeções de Filo ao argumento do desígnio}

Antes de entrar propriamente nas primeiras objeçóes de Filo ao argumento de Cleanto, importa ressaltar que o ponto crucial da crítica geral de Filo ao argumento do desígnio é formulado em termos da concepção de Hume sobre a causalidade. De acordo com esta concepçáo, a causalidade é meramente uma associaçáo colocada pela mente por meio da observação de conjunçóes constantes entre dados experienciais. A razão pela qual inferimos a existência de um arquiteto a partir da existência de uma casa é o fato de já sabermos, por meio da experiência, que casas são construídas por arquitetos, ou seja, é pressupor uma base experimental análoga. Dada esta casa particular, podemos legitimamente inferir a existência de um arquiteto porque sabemos que arquitetos são requeridos para a construção de casas. A inferência que fazemos a partir do aparente desígnio que a natureza exibe para a existência de um designer apoia-se também na pressuposiçáo de que há uma base experimental análoga. Ora, mas qual seria essa base? Segundo a argumentaçáo de Filo ela não existe, uma vez que não temos nenhuma experiência da "construção" de mundos. E se assim é, não estamos autorizados a dizer que a ordem nele observada se deve a um ser inteligente, criador ou construtor de mundos, visto que o universo é um objeto singular, individual, sem paralelo ou semelhança específica (ibid., p. 5I). E ainda que alguém possa argumentar que é justamente por não termos a experiência da construçáo de mundos que seria cabível um argumento por analogia, vale lembrar que a partir do momento em que Hume reconhece a força do argumento do desígnio, a ponto de considerá-lo o único argumento em favor da existência de Deus digno de acurado escrutínio, o desacordo entre Filo e Cleanto náo incide sobre se podemos ou não nos servir de uma analogia, visto que ela é a própria base e ponto de partida do argumento, mas sim se a analogia é suficientemente forte e concorde às regras que poderiam legitimá-la.

Pois bem, Cleanto, ao formular o argumento do desígnio, afirma que "como os efeitos são semelhantes uns aos outros, somos levados a inferir [...] de acordo com todas as regras da analogia [ênfase minha], que as causas também são semelhantes" (ibid., p. 45). Porém, até aí, Cleanto não disse quais são essas regras, o que nos dá a ocasião para perguntar: quais são as regras que legitimam uma analogia, ou melhor, quais são as regras que legitimariam precisamente essa analogia implicada no argumento do desígnio? Ou ainda, quais os critérios para se aferir a qualidade de uma analogia e as condiçôes sob as quais "argumentos a partir da experiência" podem legitimamente ser empregados? Há uma passagem na seção II da EHU na qual Hume diz:

É somente quando duas espécies de objetos encontram-se constantemente conjugadas que podemos inferir uma da outra, e se nos fosse apresentado um efeito inteiramente singular que não pudesse ser compreendido sob qualquer espécie conhecida, não vejo como formar qualquer conjetura ou inferência concernente à sua causa. Se a experiência, observação e analogia forem, de fato, os únicos guias que podemos razoavelmente seguir em inferências dessa 
natureza, tanto o efeito quanto a causa devem guardar uma similaridade e semelhança com outros efeitos e causas que conhecemos e que verificamos, em muitos casos, estarem conjugados uns aos outros (Hume, 1999b, p. 20I).

Nos Diálogos podemos encontrar uma passagem que afirma, em outras palavras, essas mesmas regras. É Filo quem fala agora:

Quando duas espécies de objetos surgem sempre conjugados, posso inferir, pelo costume, a existência de um deles onde quer que eu veja a existência do outro; e a isto chamo um argumento a partir da experiência. Mas seria difícil explicar como esse argumento pode ser aplicado a um caso como o que estamos presentemente considerando, no qual os objetos são singulares, individuais, sem paralelo ou semelhança específica (Hume, 1993, p. 5I).

Ou seja, Hume estabelece que o método que fundamenta este tipo de raciocínio deve ser sempre uma conjunção constante observada entre duas "espécies" (classes ou tipos) de "objetos" (circunstâncias ou eventos). Sendo assim, o ponto sobre o qual Hume, na voz de Filo, apoia seus argumentos é a experiência regular, repetida, frequente ou constantemente conjugada. ${ }^{5}$ No entanto, alguém poderia argumentar que Filo faz exigências excessivas ao reivindicar como suporte à analogia a experiência da construção de mundos, uma vez que a analogia vem à baila justamente para suprir a ausência de experiência causal. Nesse sentido, a questão que se impóe, como bem observa Marques, é:

Como estabelecer uma relação causal entre um objeto singular, que é o mundo, e um ato singular da criaçáo? Não temos a experiência regular de ver deuses construindo mundos; assim, o elemento de recorrência e regularidade necessário na teoria de Hume para estabelecer essa relação, está ausente, tendo de ser suprido por uma extensão analógica em direção às produçôes humanas (Marques, 2005, p. 135).

Gaskin assinala que essa é uma das poucas ocasióes em que a crítica de Hume à religião apela para teses extraídas de sua própria filosofia, neste caso, a sua análise da relação causal entre objetos. Estou de acordo com Gaskin quanto ao fato de que essa é uma das ocasióes em que a crítica de Hume à religiáo apela para teses extraídas de sua própria filosofia, mas discordo que elas sejam poucas. A meu ver, algumas teses de Hume subjazem em grande parte e em muitas ocasiôes à argumentação dos Diálogos, uma vez que os personagens, cada qual a seu modo, proferem-nas em seus discursos, ainda que nem sempre. E é claro que se o ponto crucial da crítica geral de Filo ao argumento do desígnio é formulado em termos da concepção de Hume sobre a causalidade, essa concepção deve subjazer, no mínimo, a uma boa parte da argumentaçáo. Hume traz para o debate dos Diálogos elementos contidos em teses

\footnotetext{
5 Há passagens importantes em diferentes partes dos Diálogos, bem como em outras obras de Hume que jogam um pouco de luz sobre o que seria uma legítima analogia. Cf. especialmente (D $2 \$ \$ 7-8$, p. 46); (D I2 $\$ \$ 6$ -

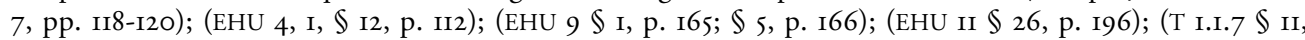
p. 20); (T I.3.9 $\$ 2$, p. 74); (T I.3.I2 $\$ 25$, p. 97).
} 
da História Natural da Religiáo (NHR), ao tratar do antropomorfismo, ou mesmo dos fatores psicológicos que nos levam a formar crenças religiosas, quando diz, na voz de Filo, por exemplo, que "o medo e a esperança têm lugar na religião" (Hume, 1993, p. I27); ou que "o terror é o princípio primordial da religiáo" (ibid., p. I28). Há também, na parte I2, discussóes sobre vários tópicos desenvolvidos (ou ao menos já esboçados) em outras obras, a saber, o da secularização da moral, da superstição e do fanatismo, da verdadeira e falsa religiáo, das disputas de palavras ou controvérsias verbais, além de, na parte I, uma discussão sobre alguns tipos de ceticismo (um tema capital em sua filosofia).

Mas o ponto nevrálgico da argumentação de Filo aqui é que para uma relação de causa e efeito entre dois objetos ser sustentada, devemos observá-los frequentemente conjugados (cf. Gaskin, I988, p. 25). No Tratado (I.3.6\$3), Hume diz que "contiguidade e sucessão não são suficientes para fazer com que declaremos que dois objetos são causa e efeito, a menos que percebamos que essas duas relaçóes se mantêm em várias instâncias" (Hume, 2002, p. 6I). E se assim é, a objeção de Humel Filo é procedente, uma vez que o argumento considera o universo como um objeto único e, de acordo com o que foi estabelecido, não é possível inferir qualquer coisa sobre a causa de um objeto único (cf. Gaskin, I988, p. 25). Assumindo-se, pois, a pertinência dessa crítica, ${ }^{6}$ a analogia segundo a qual uma casa teve certamente como causa um arquiteto ou construtor não pode ser integralmente aplicada à analogia de que o universo teve de modo similar um arquiteto ou construtor, dadas a singularidade do universo e as espantosas dissimilaridades entre a estrutura de uma casa e a estrutura do universo. Filo diz: "a desigualdade é táo marcante que o máximo que você pode pretender aqui é conjeturar, supor ou presumir a existência de uma causa similar" (Hume, 1993, p. 46).

Contudo, Cleanto argumenta em favor de uma maior semelhança entre o ajuste integral dos meios aos fins, entre uma casa e o universo e entre a ordem, proporção e arranjo de cada uma de suas partes (ibid.). Vale dizer que ele não deixa de admitir as dissimilaridades (ou imperfeiçóes na analogia) existentes entre o universo e uma casa. No entanto, Cleanto defende que nem todas as dissimilaridades enfraquecem

\footnotetext{
6 Esta crítica (que assumo também como procedente) não está de modo algum livre de controvérsias. No entanto, para não desviar de meus propósitos, faço aqui economia do debate em torno dos problemas que essa crítica suscita. Para uma discussão cuidadosa e aprofundada sobre este tópico, ver Gaskin (1988, pp. 25-27); Pike (I970, pp. I29-I37); Yandell (I990, pp. I73-I83); Flew (I961, p. 23I); Barra (2002, pp. I63-I64). Lebrun (1993) promove uma análise pontual, com base em definiçôes de Hume e Kant, do que seria uma legítima analogia. Diz Lebrun: "o emprego da analogia só é lícito entre termos pertencentes ao mesmo gênero ontológico, como indica a Logik" (I993, p. 298); e, ainda, "para supor em Deus mais do que o permite o único efeito conhecido, seria preciso entáo que o efeito e a causa presumida (o mundo e Deus) fossem da mesma espécie ou do mesmo gênero que um efeito e uma causa observáveis e conjuntos na experiência; ora, o mundo é um efeito singular que não se pode compreender sob nenhuma espécie conhecida, de modo que todo raciocínio que conclui uma propriedade de seu autor fundando-se sobre uma semelhança com uma causalidade observável é 'evidentemente contrário a todas as regras da analogia"” (ibid., p.305).
} 
um argumento por analogia. Ora, como assim? Yandell (1990, p. 174) parece encontrar uma boa maneira de explicar o que Cleanto defende: pedras, diz Yandell, podem ser dissimilares nas cores, no peso, no tamanho, na forma e no valor. Porém, todas caem ao serem lançadas ao ar. O universo e uma casa são dessemelhantes no tamanho, na magnitude. Porém, ambos são semelhantes no que tange à ordem, propósito ou desígnio. Uma casa é composta de madeira, cimento, tijolos e pregos. Não contém zebras nem galáxias. Já o universo contém, entre seus componentes, galáxias e zebras, tanto quanto tijolos, madeiras, cimento, casas e pregos. Diversos como eles são, uma casa e o universo possuem ordem, planejamento e desígnio. E isso é o que Cleanto afirma ser suficiente para legitimar a hipótese do desígnio - precisamente um dos principais pontos de discordância entre ele e Filo. Este último considera ilegítima a comparação entre relaçôes naturais e produtos do engenho humano, visto que ambos pertencem a gêneros ontológicos distintos, quer dizer, uma relação é natural e a outra artificial.

Para dar força à sua crítica, Filo dissera pretender argumentar no "terreno do próprio Cleanto" (Hume, I993, p. 47), recorrendo a princípios epistemológicos sobre os quais ambos concordam. Eles estão de acordo, por exemplo, quanto ao fato de que não podemos determinar a priori que tipo de universo é ou não possível, uma vez que, nas palavras de Filo, "só a experiência pode apontar a verdadeira causa de qualquer fenômeno" (ibid.). Filo já argumentara que se alguém fizesse abstração da experiência, "de tudo o que sabe ou viu" (ibid.), não haveria qualquer razão imparcial para aderir a uma ideia ou sistema e rejeitar outros, "pois, já que nada daquilo que ele concebe claramente pode ser tomado como impossível, ou como algo que implica contradição, todas as quimeras de sua imaginação estariam em pé de igualdade" (ibid.). A imaginação "poderia fornecer uma infinita variedade de relatos e representaçôes, todas igualmente possíveis" (ibid.). E justamente por serem todas igualmente possíveis tornar-se-ia impossível chegar por si mesmo a uma explicação satisfatória de por que preferir uma ideia ou sistema aos restantes (ibid. ). Filo defende que "pensamento, propósito, inteligência, tal como encontramos nos homens e nos outros animais, não são mais do que uma das fontes e princípios do universo, assim como [...] centenas de outros que são diariamente observados" (ibid. , p. 49). Segue-se, pois,

Que a ordem, arranjo ou ajustamento das causas finais não constituem por si sós quaisquer provas de desígnio [...]. Por tudo que podemos saber a priori, a matéria pode conter originalmente em si mesma a fonte ou princípio da or$\mathrm{dem}$, tanto quanto a mente os contém; e náo há mais dificuldade em conceber que os diversos elementos possam, a partir de uma causa interna desconhecida, produzir a mais extraordinária organização, do que conceber que as ideias, no interior da grande mente universal, possam se organizar da mesma maneira, a partir de uma semelhante causa interna desconhecida (Hume, 1993, p. 48). 
Eis aí um primeiro esboço da famosa hipótese da matéria (que será melhor formulada e desenvolvida em D $8 \$ \$$ I-8, pp. 84-87) como uma possível fonte ou princípio da ordem do universo. ${ }^{7}$ Note-se que a tese acima não favorece aqueles que defendem que a ordem seja inerente apenas à mente ou pensamento, tampouco os que defendem que a ordem seja inerente à matéria. A igual possibilidade dessas duas suposiçóes (mente e matéria) é, assim, admitida, o que torna perfeitamente plausível a hipótese segundo a qual o designer inteligente não é a única explicação possível da ordem que encontramos no mundo (ibid., p. 48). Esta é mais uma tese sobre a qual Filo vai insistir, propondo um número considerável de hipóteses cosmogônicas rivais à do desígnio, a fim de mostrar que "uma suspensão integral do juízo é, aqui, nosso único recurso razoável” (ibid., p. 88).

\section{Efeitos semelhantes requerem causas semelhantes}

$\mathrm{Na}$ parte 5 Filo pede a Cleanto que inspecione melhor o princípio ou "argumento experimental" segundo o qual "efeitos semelhantes requerem causas semelhantes", ou, em outras palavras, "a semelhança dos efeitos prova a semelhança das causas" (like effects prove like causes) (ibid., p. 67). Para assentar as bases da discussáo Filo recorre ao princípio da proporcionalidade entre a causa e o efeito. Este princípio reza que "quanto maior a semelhança dos efeitos que são vistos, e a semelhança das causas que são inferidas, mais forte é o argumento, e que, portanto, qualquer afastamento diminui a probabilidade e torna o experimento menos conclusivo" (ibid.). Com essa regra em mãos, Filo vai extrair as consequências que se seguem dos princípios que Cleanto assumiu (like effects prove like causes). Antes disso, ele estrategicamente leva Cleanto a reconhecer a necessidade de estreitar ao máximo a semelhança entre a mente divina e a mente humana, ou seja, de que "quanto mais semelhante melhor" (the liker the better) (ibid., p. 68). Mas ele faz isso para defender a tese contrária: a de que "a causa universal de tudo é vastamente diferente da humanidade ou de qualquer objeto da experiência ou observação humanas” (ibid.).

Primeiramente Filo mostra que o método de raciocínio adotado por Cleanto obriga-o a renunciar a toda pretensão de infinitude em qualquer dos atributos da divindade. Ora, se quanto mais semelhante melhor, a suposta inteligência e benevolência divinas não podem ser infinitas, sua perfeição também não, tampouco o seu poder, pois se a causa deve ser proporcional ao efeito, e o efeito, à medida que cai sob nosso conhecimento não é infinito, não há como atribuir tal qualidade ao

\footnotetext{
A hipótese da matéria levantada nos Diálogos é assunto para discussóes pontuais que não deverão aqui ser tratadas. Limito-me a apenas assinalar o principal ponto sobre o qual versam tais discussóes, a saber, se Hume ofereceu ou não um pequeno anúncio, ainda que embrionário, da "perigosa ideia" de Darwin - a tese anticriacionista da seleção natural. Para uma discussão sobre esse tópico ver: Silva, 2006; Marques, 2005; Barra, 20II; Dawkins, 2007; Dennett, I998; Monteiro, 2009.
} 
ser divino (ibid.). ${ }^{8}$ Nesse sentido, ao aproximar demais a mente divina da mente humana com base no princípio de que "quanto mais semelhante melhor", Cleanto acaba distanciando excessivamente a divindade da concepção teísta. Pois se a regra que fortalece o argumento é a proporcionalidade entre a causa e o efeito, um efeito finito pede uma causa finita para manter-se nos limites da proporção. Se quisermos insistir nessa regra temos de tornar os atributos divinos finitos, tais como os dos seres humanos. A consequência que se segue é a de que pensar numa divindade finita é afastá-la demasiadamente da divindade concebida pela teologia natural (que é precisamente aquela que se pretende estabelecer). Portanto, essa linha de argumentaçáo conduz Cleanto a abandonar progressivamente os atributos divinos. Assim sendo, embora a argumentação incida sobre a natureza divina, leva, ao mesmo tempo, ao enfraquecimento das provas de sua existência.

Segundo Filo, outra consequência inconveniente que se segue do antropomorfismo de Cleanto é a de que ele "não teria nenhuma razão para atribuir perfeição à Divindade, ainda que em sua capacidade finita, ou supor que ela fosse livre de erros e incoerências em seus empreendimentos" (Hume, 1993, p. 68), visto que os homens são imperfeitos, erram e são, também, muitas vezes, incoerentes. Ora, se admitirmos a priori um autor perfeito da natureza, os muitos defeitos que ela nos apresenta teriam de ser vistos apenas como defeitos aparentes. E ainda que pudéssemos dizer que "este mundo é uma produção perfeitíssima", prossegue Filo, "restaria ainda a incerteza de que todas as suas excelências pudessem com justiça ser atribuídas ao artífice" (ibid., p. 69). Filo alega que o artífice desse suposto mundo perfeitíssimo poderia ter imitado e copiado artífices anteriores a ele, que vieram, gradativamente, aperfeiçoando a arte de construir mundos por meio de "múltiplas tentativas, erros, correçôes, decisões e controvérsias" (ibid.). Dentre o "grande número de hipóteses que poderiam ser propostas, e um número maior ainda de outras que poderiam ser imaginadas", questiona Filo, "quem pode determinar onde reside a verdade, ou melhor, quem pode conjeturar qual das hipóteses é mais provável” (ibid.)?

\footnotetext{
8 Vale conferir o artigo de John Beaudoin (I999) sobre algumas críticas desferidas por Richard Swinburne ao princípio de proporcionalidade entre a causa e o efeito, do qual Hume se serve em sua investida contra o argumento do desígnio na seçáo II da EHU e também nesta parte 5 dos Diálogos. Na EHU II $₫$ I2, o amigo epicurista de Hume estabelece que "quando inferimos qualquer causa particular de um efeito, devemos guardar a proporção entre eles, náo sendo jamais permitido atribuir à causa quaisquer qualidades que náo sejam precisamente aquelas suficientes para produzir o efeito. [...] e que se a causa atribuída a algum efeito não for suficiente para produzi-lo, devemos ou rejeitar essa causa ou acrescentar-lhe qualidades que a tornem corretamente proporcional ao efeito" (Hume, I999b, p. 190). Segundo Beaudoin, a relevância deste princípio para o argumento do desígnio é óbvia, pois se a reflexão sobre as características do mundo não indica que para formá-lo são requeridos um perfeito poder, conhecimento e benevolência, o argumento do desígnio náo fornece fundamentos para afirmar a existência de um criador (ou criadores) com esses atributos. Neste artigo, Beaudoin (1999, pp. 27-28) defende uma versão levemente modificada desse princípio que, de acordo com ele, captura o significado dado a ele por Hume, e evita as várias tentativas de Swinburne de contrariar o uso desse princípio contra as formas a posteriori da teologia natural, ou colocando em questão a sustentabilidade desse princípio como um princípio epistêmico, ou apelando para considerações que poderiam sobrepujá-lo.
} 
Embora a questão acima pareça retórica - pois alguém bem poderia responder: ora, determinar a verdade é difícil, mas conjeturar qual das hipóteses é mais provável, isso qualquer sujeito que pensa, examina e avalia a consistência das hipóteses disponíveis poderia fazer - creio que ela cumpre o papel de nos fazer reconhecer uma isostenia entre a hipótese do desígnio e as hipóteses que Filo propóe. Ao menos é o que Filo defende. A meu ver, as hipóteses de Filo visam a mostrar que, de acordo com o método de Cleanto, todas elas, por mais extravagantes que possam parecer, são tão plausíveis quanto à hipótese do desígnio. ${ }^{9} \mathrm{E}$ malgrado eu defenda aqui que Filo, de modo coerente com os princípios estabelecidos para a discussão, argumenta nesse sentido, considero difícil pensar (de um ponto de vista do homem comum, bem entendido) que a hipótese segundo a qual este mundo é um animal e que um cometa é o ovo deste animal (Ibid. , p. 79), por exemplo, seja táo plausível quanto à hipótese do desígnio. Ela parece agredir o senso comum. Intuitivamente a hipótese do desígnio parece mais plausível e de acordo com o que podemos observar no mundo. O próprio Filo reconhece, e não apenas uma vez, que

Em muitos aspectos do universo e de suas partes, particularmente dessas últimas, a beleza e o ajuste das causas finais impressionam-nos com uma força de tal modo irresistível, que todas as objeçóes aparecem como meras cavilaçóes e sofismas (o que, de fato, acredito que elas realmente são), e não podemos sequer imaginar como nos seria possível atribuir-lhes algum peso (Hume, I993, p. I03). ${ }^{10}$

Outro atributo divino que se encontra comprometido com o método de raciocínio de Cleanto é a unidade, uma vez que, em geral, a construçáo de casas, navios e cidades é feita por vários homens. Por que, então, pergunta Filo, "várias divindades não poderiam ter se associado para arquitetar e edificar um mundo" (ibid., p. 69)? Ele argumenta que há muitas vantagens nessa suposição, pois, além da divisão do trabalho nos livrar do vasto poder e inteligência que seria preciso supor no caso de haver apenas uma divindade, a associação de várias deidades nos conduziria a uma semelhança ainda maior com a que ocorre nos empreendimentos humanos (ibid., pp. 69-70). Filo, aqui, recorre à Navalha de Ockham ao relembrar que "multiplicar as causas desnecessariamente é, na verdade, contrário à genuína filosofia, mas que este princípio não se aplica no presente caso, uma vez que isso [isto é, uma associação

9 Alinho-me aqui à interpretação de Barra (20II), segundo a qual "os desafios de Philo repetem uma consagrada estratégia argumentativa cética: promover a polifonia (diaphonia), isto é, a multiplicidade dos discursos e das razóes a fim de favorecer a percepçáo da igual força (isosthéneia) das partes em conflito" (p. 7). Na parte I, $\$$ II dos Diálogos, há mais uma interessante passagem que pode ser oferecida como abono a essa interpretação. (Cf. Groulez, 2005, pp. 93-IO2).

${ }^{10}$ As concessóes que Filo faz ao argumento do desígnio levam-nos diretamente ao problema de interpretaçáo que surge de sua aparente mudança de posição na parte I2 dos Diálogos. Após criticar o argumento do desígnio nas partes 2 a 8 e IO e II, Philo, na parte I2, empreende um discurso, digamos assim, de reconciliaçáa com Cleanto, assentindo, ao final, aos princípios propostos por seu adversário. Se esse é um assentimento aparente, retórico, estratégico, irônico ou verdadeiro é matéria para discussóes pontuais que aqui não serão desenvolvidas. 
de várias deidades] está mais de acordo com a experiência humana” (Ibid., p. 70). Ademais, continua Filo,

Os seres humanos são mortais e renovam sua espécie pela geração - algo que
é comum a todas as criaturas vivas. Por que, entâo, dever-se-ia excluir essa
condiçấo tão universal e essencial daquelas deidades numerosas e limitadas?
[...]. E por que não se tornar um antropomorfista completo? Por que náo
considerar a divindade ou divindades como sendo corpóreas, possuidoras de
olhos, nariz, boca, ouvidos, etc.? ( Hume, I993, p. 70).

Filo argui que este mundo é muito falho e imperfeito se comparado a um padrão superior. Nesse caso, teríamos de reconhecer que suas falhas e imperfeiçóes poderiam ser o resultado de "um ensaio rudimentar de alguma deidade infantil" [...] ou "obra de alguma deidade inferior e subalterna", ou, ainda, "produto da senilidade de alguma deidade decrépita" (ibid., p. 7I). De acordo com Filo, a partir do momento em que se supóe que os atributos divinos têm caráter finito, todas essas suposiçôes têm lugar. Em vista disso, "sustentar um sistema teológico tão bárbaro e incerto não pode ser, sob qualquer aspecto, preferível a não sustentar nenhum" (ibid.), pois se o conhecimento da divindade é possível apenas a partir da observação e experiência, os atributos divinos não podem ser garantidos, a menos que eles sejam provados a priori - uma perspectiva decididamente fora do escopo pretendido pelos dois debatedores.

Mas Cleanto rejeita todas as suposiçóes de Filo oferecendo apenas uma réplica: que Filo, com todas as suas extravagantes suposiçôes, não consegue se livrar da hipótese do desígnio. Ora, como náo? Para Cleanto, as hipóteses de Filo, ao conterem "algo como desígnio", conduzem-no a cada passo a recorrer à hipótese do desígnio. E isso seria um fundamento suficiente para a religiâo ( $i b i d$.$) . Bom, mas alguém pode-$ ria perguntar: quer dizer, Cleanto, que basta para fundamentar a religiáo que as hipóteses contenham "algo como desígnio"? Isso não seria afrouxar demais suas pretensôes?

É interessante notar que Filo levanta várias questôes que não são propriamente respondidas. Sua estratégia é perguntar: por que não poderíamos pensar que...? Por que tal coisa não poderia ter sido feita de outro modo? Por que tal coisa não poderia ser diferente? Ora, nós podemos pensar tudo isso: as hipóteses propostas por Filo são todas pensáveis sem propriamente implicar contradiçôes. De um ponto de vista da razão especulativa, todas elas são plausíveis e, num certo sentido, estão de acordo com a experiência, ao menos em seu ponto de partida. $\mathrm{O}$ que vem depois desse ponto de partida é meramente a possibilidade lógica de tais hipóteses, e não a possibilidade real. Filo não está a propor seriamente as hipóteses da geração e vegetação (apresentadas nas partes 6 e 7), mas apenas tentando mostrar que elas são logicamente possíveis (porque pensáveis) e que não dispomos de dados suficientes para determinar qual o princípio originário do universo. Na verdade, todas elas são parciais e arbitrárias. Nenhuma pode provar que Deus existe e é o princípio originário de todas as coisas, assim como o argumento do desígnio também não pode. 
Certamente Hume náo aprovaria a maior parte das ideias e teorias kantianas, mas talvez valha a pena recorrer aqui às seguintes passagens da Crítica da Razão Pura, relativas à diferença entre "possibilidade lógica" e "possibilidade real" de um objeto. No prefácio à $2^{\mathrm{a}}$ edição Kant diz:

Para conhecer um objeto requer-se que eu possa provar sua possibilidade (seja pelo testemunho da experiência a partir da sua realidade, seja a priori pela razão). Mas posso pensar o que quiser desde que não me contradiga, isto é, quando o meu conceito for apenas um pensamento possível, embora eu não possa garantir se no conjunto de todas as possibilidades lhe corresponde ou não um objeto. Mas requerer-se-á algo mais para atribuir validade objetiva (possibilidade real, pois a primeira era apenas lógica) a um tal conceito (Kant, 1994, p. I6n).

É claro que a ideia de um “a priori pela razão" está fora da perspectiva de Hume, que admitiria apenas o testemunho da experiência, mas creio que a explicação kantiana ilumina um pouco o que está implicado nos argumentos de Filo, na medida em que, pode-se dizer, há possibilidade lógica em suas hipóteses. Mas poder-se-ia dizer que há alguma possibilidade real? E se há, quão realmente possíveis elas seriam? Isso não significa que Filo está desavisado disso, ao contrário, a meu ver, Filo procede deste modo com o intuito de mostrar a Cleanto uma das falhas de sua hipótese.

Em suma, e para encerrar, o que se segue da argumentação de Filo é que o método de raciocínio empregado por Cleanto compromete, ao menos em algum sentido, a atribuiçáo de infinitude, perfeição, unidade, eternidade, imortalidade e imaterialidade ao ser divino - precisamente as consequências inconvenientes dos princípios que o próprio Cleanto estabeleceu para a discussão. Ele teria de destituir o ser divino de várias qualidades que lhe são essenciais. E se não podemos atribuir à divindade tais qualidades, é evidente que já não estamos mais a falar do Deus tradicional que se pretende estabelecer com o argumento do desígnio.

\section{Referências bibliográficas}

BARRA, E. (2OII). "Quando criacionismo e evolucionismo tornam-se indistintos: liçóes a partir da crítica de David Hume às explicaçóes da natureza em sua totalidade”. In: Contexto \& Educação, 26 (86), pp. 4-22.

Beaudoin, J. (I999). "On Some Criticisms of Hume's Principle of Proportioning Cause to Effect”. In: Filo, vol. 2, n. 2, pp. 27-4I.

DaWkins, R. (2007). Deus, um delírio. Tradução de Fernanda Ravagnani. São Paulo: Cia das Letras.

DennetT, D. C. (1998). A perigosa ideia de Darwin: a evolução e os significados da vida. Tradução de Talita M. Rodrigues. Rio de Janeiro: Rocco. 
Ferraz, M. C. de (2012). Existência de Deus, Natureza Divina e a Experiência do Mal nos Diálogos de Hume. $194 \mathrm{f}$. (Tese de doutorado em filosofia defendida na Faculdade de Filosofia, Letras e Ciências Humanas da Universidade de São Paulo - USP).

FLEW, A. (196I). Hume's Philosophy of Belief: A Study of his First Inquiry. London: Routledge \& Kegan Paul.

Groulez, M. (2005). Le scepticisme de Hume. Paris: PUf.

Hume, D. (1988). Dialogues Concerning Natural Religion. New York: Macmillan Publishing Company.

Hume, D. (1992). Diálogos sobre a Religião Natural. Tradução de José Oscar de Almeida Marques. São Paulo: Martins Fontes.

Hume, D. (1993). Dialogues Concerning Natural Religion and The Natural History of Religion. Oxford: University Press.

Hume, D. (1999a). An Enquiry concerning Human Understanding. Oxford: University Press.

Hume, D. (1999b). Investigação sobre o Entendimento Humano. Tradução de José Oscar de Almeida Marques. São Paulo: EdunESP.

Hume, D. (200I). Tratado da Natureza Humana. Tradução de Déborah Danowski. São Paulo: EdUNESP.

Hume, D. (2002). A Treatise of Human Nature. Edited by D. F. Norton \& M. J. Norton. Oxford: University Press.

Kant, I. (1994). Crítica da Razão Pura. Tradução de M. P. dos Santos e A. F. Morujão. Lisboa: Calouste Gulbenkian.

Lebrun, G. (1993). Kant e o Fim da Metafísica. Tradução de Carlos Alberto Ribeiro de Moura. São Paulo: Martins Fontes.

MARQues, J. O. de A. (2005). "A crítica de Hume ao argumento do desígnio". In: Dois pontos, I, vol. 2, pp. I29-I47.

MerriLl, K. R. (2008). Historical Dictionary of Hume's Philosophy. Historical Dictionaries of Religions, Philosophies, and Movements, n. 86. Lanam/Toronto/Plymouth: The Scarecrow Press, Inc.

Monteiro, J. P. (2009). Hume e a Epistemologia. São Paulo: EdUnESP/Discurso Editorial.

PIKE, N. (I970). “Hume on the argument from design”. In: PIKE, N. (ed.), Dialogues Concerning Natural Religion. New York: BobbsMerrill Company, pp. 127-238.

Silva, M. R. da (2006). "Hume e o argumento do desígnio". In: Kriterion, vol. 47 (II3), pp. II5-I3O.

YANDELl, K. E. (I990). Hume's “Inexplicable Mystery". Philadelphia: Temple University Press. 